Gut, 1984, 25, 26-31

\title{
Sulphated bile acids in duodenal juice of healthy infants and children compared with sulphated bile acids in paediatric patients with various gastroenterological diseases
}

\author{
K H NIESSEN, M TEUFEL, AND G BRÜGMANN \\ From the University Children's Hospital, Tübingen, Federal Republic of Germany
}

SUMmARY The bile acid pattern in the first 10 minute fraction of intestinal juice after injection of pancreozymin ( $2 \mathrm{U} / \mathrm{kg}$ bw) was studied in 32 gastroenterologically healthy children and 26 paediatric patients with various diseases of the liver or intestine. The sulphated and non-sulphated portions of monohydroxy, dihydroxy, and trihydroxy bile acids were evaluated in relation to the total concentration of bile acids as well as the ratios of the individual acids to each other in esterified and unesterified form. In healthy patients, the extent of sulphation was not age dependent. The quantity of potentially toxic monohydroxy and dihydroxy bile acids did not determine the percentage of sulphation, which was induced only by the severity of cholestasis. Ursodeoxycholic bile acids were usually esterified with sulphuric acid to a remarkably high degree. Less sulphated bile acids were detected in patients with coeliac disease than in the control group.

Sulphate esters of bile acids are usually less toxic than their unesterified parent substances. ${ }^{1}$ They are also eliminated more rapidly through faeces and urine $^{2}$ so that the organism can be effectively detoxified in case of cholestasis. In man, these esters are synthesised primarily in the liver, but also in the small bowel mucosa and the suprarenal glands. They are apparently not formed in the kidneys, as is the case in rats. ${ }^{3-5}$ It has been assumed that the extent of sulphation depends on the number as well as the position and configuration of the hydroxyl groups in the bile acid skeleton. ${ }^{6}$ The activity of the responsible sulphotransferase therefore varies depending on the substrate. ${ }^{7}$ Despite these and other new discoveries, the metabolism of bile acid sulphates has not been fully clarified; information on infants and children is particularly sparse. The few available studies deal primarily with the cholestatic syndromes. ${ }^{8-12}$ Other gastroenterological diseases have not been investigated, even though earlier studies indicate disturbances of bile acid metabolism in patients with - for example, coeliac disease or cystic fibrosis. ${ }^{13-16}$

Address for correspondence: Prof K H Niessen, Universitäts-Kinderklinik. Rümelinstrasse 23, D-7400 Tübingen, Federal Republic of Germany. Received for publication 30 March 1983.
Our study deals primarily with the metabolism of bile acid sulphates. Intestinal juice was examined to determine age related effects and specific alterations caused by various diseases of the intestine and liver.

\section{Methods}

\section{METHODS}

Secretin-pancreozymin tests $(S P \text { tests })^{17}$ were carried out in the course of a gastroenterological examination of 58 infants and children between 2 months and 15 years of age. The diagnostic procedure was carefully explained to the parents and all consented to this examination. Gastroenterological diseases were excluded in 32 cases by laboratory and bacteriological tests as well as ultrasound, radiography, and biopsies of the small intestine. Eight of these children were infants (A; mean age 7 months; $S D=4)$ and 24 were over the age of 1 year (B; mean age 4 years 4 months; $S D=3$ years four months). Subtotal villous atrophy of the small bowel mucosa was present in nine patients (coeliac disease; mean age 7 years 2 months; $S D=5$ years 1 month), which proved to be gluten induced. Seven children between 8 years 11 months and 13 years 2 months of age (mean age 10 years 9 months; 
$\mathrm{SD}=2$ years 1 month) were known to have cystic fibrosis. Abdominal ultrasound evaluation of these patients suggested fibrotic-cirrhotic changes of liver tissue, although the liver enzymes were within normal range. Four infants with short bowel syndrome, whose small bowel, including the ileocaecal valve, was resected to a length of $53 \mathrm{~cm}$ or less in the first days of life because of volvulus, gastroschisis, or necrotising enterocolitis, were examined at the ages of 5 to 9 months. Secretinpancreozymin tests were carried out in three infants with extrahepatic biliary atresia who had undergone a Schweizer ${ }^{18}$ hepatoportolymphodigestive bile drainage and in three other patients with intrahepatic cholestasis to investigate bile flow into the duodenum. Two of these infants suffered from alpha-1-antitrypsin deficiency and one from Alagille's disease.

In accordance with Burton et al, ${ }^{17}$ one tube was put into the stomach and another into the distal part of the duodenum. The tubes were positioned under fluoroscopic control. Fasting stomach contents and duodenal juice were obtained by mechanical aspiration. After collection of two 10 minute fractions of each specimen, $2 \mathrm{U} / \mathrm{kg}$ of secretin (Boots) were given intravenously. Three 10 minute fractions were then collected. Thereafter, $2 \mathrm{U} / \mathrm{kg}$ of pancreozymin were injected and the secretory products collected separately in three 10 minute fractions. The bile acid pattern was evaluated in the first fraction after pancreozymin injection, whereas pancreatic enzymes were elaborated in all fractions.

Because of their different molecular size and polarity, the bile acids, extracted with chloroformmethanol $(1: 1,0.01 \mathrm{~N} \mathrm{NaCl})$, could be separated into two fractions with column chromatography (Sephadex LH 20). ${ }^{19}$ The first fraction contained non-conjugated and non-sulphated acids, glycoconjugated and tauroconjugated bile acids, and glucuronide metabolites; the second fraction, bile acid sulphates. After separation with thin layer chromatography, the glycine and taurine derivatives of cholic and lithocholic acids as well as the non-conjugated bile acids could be measured fluorimetrically with a chromatogram spectrophotometer (Zeiss KM 3) directly on to a thin layer plate. All other derivatives had to be broken down into these measurable substances. ${ }^{2021}$ The glycoconjugates and tauroconjugates therefore were hydrolysed ${ }^{22-24}$ and the sulphates additionally dissolved. ${ }^{19}{ }^{25} \mathrm{~A}$ total of 34 different bile acids in each specimen were evaluated quantitatively with our method (for details, see ref 26). The glucuronides were not analysed. Separation of the monohydroxy bile acids (Mono) to lithocholic acids, allo-lithocholic acids, and 3-beta-hydroxy-5-cholenic acids was impossible.
The bile acid pattern was calculated in percentages of individual acids in the total concentration. ${ }^{27} 28$ The molecular concentrations of all bile acids measured in the specimen therefore were added together and the sum adjusted to $100 \%$. The percentages of cholic acids, chenodeoxycholic acids, deoxycholic acids, ursodeoxycholic acids, and monohydroxycholic acids (Mono) were calculated on the basis of this total sum (Table). The acids were not further classified into glycoconjugated or tauroconjugated bile acids. Instead, a clear distribution of sulphated and non-sulphated bile acids was established, and the relationship of these acids to each other was expressed in percentages. The sum of the sulphated and non-sulphated fractions for each individual bile acid was adjusted to $100 \%$ on the basis of the mean values (Table). In this way, the distributions of sulphated and non-sulphated portions for each bile acid and group of acids listed in Figures 1 and 2 were obtained in percentages.

All mean values of the groups were analysed with the Student's $t$ test to establish any significant differences. The Welsh ${ }^{29}$ approximation was used with unequal variances ( $F$ test). When $k-1$ patient groups were compared with one control group (A or $B)$, the equation

$$
\alpha=1-\sqrt{ } / 0.95
$$

was selected for the single test to ensure a total probability of error of $0 \cdot 05 .{ }^{30}{ }^{31}$ The symbol ' $\mathrm{s}$ ' in the Table designates a significant difference with a $5 \%$ probability of error.

\section{Results}

Three to eight per cent of all bile acids in the duodenal juice of healthy infants and children were esterified with sulphate, regardless of the age of the child (Table: A, B). In relation to the total amount, the individual acids were sulphated to a small extent and the extent of the sulphation did not differ appreciably $(0 \cdot 34 \%-2 \cdot 2 \%)$. There were marked differences, however, in the ratio of sulphated to non-sulphated portions of the individual bile acids (Figs 1 and 2): a total of $3 \%$ of the trihydroxy bile acids (C) and more than $50 \%$ of all monohydroxy bile acids (Mono) were sulphated. The dihydroxy bile acids were located between these extremes: chenodeoxycholic acids showed the least $(4.0 \%-$ $4.7 \%)$ and ursodeoxycholic acids the highest (13\%$15 \%)$ sulphation. The preference of the monohydroxy acids for esterification with sulphate is also illustrated by the fact that the portion of these acids is higher after the first year of life $(61.5 \%)$ than during the first 12 months, even though less monohydroxy bile acids are formed after the first year of 
Table Percentages of single bile acids in total concentration $(\bar{x} \pm s)$

\begin{tabular}{|c|c|c|c|c|c|c|c|c|}
\hline \multirow{2}{*}{$\begin{array}{l}\text { Group } \\
(n)\end{array}$} & \multirow{2}{*}{$\begin{array}{l}\text { Total bile acid } \\
\text { concentration* } \\
(\mu \mathrm{M} / \mathrm{ml})\end{array}$} & & \multicolumn{6}{|l|}{ Percentages } \\
\hline & & & C & $C D C$ & $D C$ & $U D$ & Mono & Total \\
\hline A & $30 \cdot 2$ & $\mathbf{a}$ & $1 \cdot 2 \pm 0 \cdot 9$ & $1 \cdot 8 \pm 1 \cdot 0$ & $0.34 \pm 0.23$ & $0.44 \pm 0.22$ & $2 \cdot 2 \pm 1 \cdot 5$ & $6 \cdot 0 \pm 2 \cdot 1$ \\
\hline$(n=8)$ & $23 \cdot 7,36 \cdot 6+$ & b & $45 \cdot 9 \pm 10 \cdot 2$ & $38 \cdot 4 \pm 8 \cdot 4$ & $3 \cdot 9 \pm 2 \cdot 5$ & $2 \cdot 9 \pm 2 \cdot 7$ & $2 \cdot 3 \pm 1 \cdot 5$ & $93.4 \pm 13.9$ \\
\hline EBA & $0 \cdot 80$ & $\mathrm{a}$ & $3 \cdot 8 \pm 1.9 \mathrm{~s}$ & $24 \cdot 8 \pm 7 \cdot 8 \mathrm{~s}$ & $7 \cdot 1 \pm 3 \cdot 2 \mathrm{~s}$ & $1 \cdot 7 \pm 1 \cdot 6$ & $14 \cdot 3 \pm 11 \cdot 1$ & $51 \cdot 7 \pm 14 \cdot 3 \mathrm{~s}$ \\
\hline$(n=3)$ & $0 \cdot 59,1 \cdot 1$ & b & $3 \cdot 0 \pm 2 \cdot 1 \mathrm{~s}$ & $27 \cdot 3 \pm 12 \cdot 1$ & $4 \cdot 4 \pm 4 \cdot 2$ & $3 \cdot 8 \pm 2 \cdot 1$ & $9 \cdot 5 \pm 3 \cdot 3 \mathrm{~s}$ & $48 \cdot 0 \pm 17 \cdot 3 \mathrm{~s}$ \\
\hline IHC & $2 \cdot 8$ & $\mathbf{a}$ & $2 \cdot 4 \pm 1.6$ & $8 \cdot 5 \pm 3 \cdot 5 \mathrm{~s}$ & $4 \cdot 1 \pm 2 \cdot 3 \mathrm{~s}$ & $7 \cdot 3 \pm 4 \cdot 0 \mathrm{~s}$ & $1 \cdot 6 \pm 1 \cdot 0$ & $24 \cdot 0 \pm 6 \cdot 5 \mathrm{~s}$ \\
\hline$(n=3)$ & $2 \cdot 0,4 \cdot 4$ & b & $9 \cdot 2 \pm 5 \cdot 7 \mathrm{~s}$ & $41 \cdot 9 \pm 16 \cdot 4$ & $10 \cdot 6 \pm 4 \cdot 6 s$ & $3 \cdot 5 \pm 3 \cdot 1$ & $11 \cdot 2 \pm 3.4 \mathrm{~s}$ & $76 \cdot 0 \pm 21 \cdot 5$ \\
\hline SB & $31 \cdot 8$ & $\mathrm{a}$ & $0.67 \pm 0.39$ & $1.4 \pm 0.95$ & $0 \cdot 32 \pm 0 \cdot 20$ & $1.0 \pm 0.6$ & $0.74 \pm 0.33$ & $4 \cdot 1 \pm 1 \cdot 5$ \\
\hline$(n=4)$ & $28 \cdot 7,34 \cdot 9$ & $\mathrm{~b}$ & $29 \cdot 4 \pm 5 \cdot 9$ & $50 \cdot 4 \pm 14 \cdot 2$ & $4 \cdot 6 \pm 2 \cdot 1$ & $1 \cdot 8 \pm 1.4$ & $10 \cdot 0 \pm 3 \cdot 9$ & $96 \cdot 2 \pm 22 \cdot 3$ \\
\hline B & $42 \cdot 3$ & $\mathbf{a}$ & $1 \cdot 1 \pm 0 \cdot 9$ & $1 \cdot 8 \pm 1 \cdot 2$ & $0 \cdot 60 \pm 0.41$ & $0 \cdot 47 \pm 0.34$ & $1 \cdot 1 \pm 0 \cdot 4$ & $5 \cdot 1 \pm 1 \cdot 8$ \\
\hline$(n=24)$ & $40 \cdot 8,51 \cdot 8$ & $b$ & $36 \cdot 0 \pm 10 \cdot 8$ & $44 \cdot 1 \pm 9 \cdot 4$ & $10 \cdot 5 \pm 5 \cdot 6$ & $2 \cdot 6 \pm 2 \cdot 3$ & $0.66 \pm 0.12$ & $93 \cdot 8 \pm 15 \cdot 6$ \\
\hline Coe & $62 \cdot 7$ & $\mathbf{a}$ & $0.71 \pm 0.54$ & $1 \cdot 4 \pm 1 \cdot 2$ & $0.34 \pm 0.30$ & $0 \cdot 28 \pm 0 \cdot 22$ & $0.53 \pm 0.31 \mathrm{~s}$ & $3.3 \pm 1.6 \mathrm{~s}$ \\
\hline$(n=9)$ & $58 \cdot 7,66 \cdot 7$ & $\mathrm{~b}$ & $44 \cdot 2 \pm 14 \cdot 4$ & $37 \cdot 1 \pm 10 \cdot 6$ & $8 \cdot 6 \pm 8 \cdot 2$ & $5 \cdot 6 \pm 3 \cdot 1 \mathrm{~s}$ & $1 \cdot 3 \pm 1 \cdot 3$ & $96 \cdot 8 \pm 22 \cdot 1$ \\
\hline $\mathrm{CF}$ & $33 \cdot 6$ & $\mathbf{a}$ & $2 \cdot 9 \pm 2 \cdot 0$ & $5 \cdot 0 \pm 2 \cdot 7 \mathrm{~s}$ & $2 \cdot 4 \pm 1 \cdot 8 \mathrm{~s}$ & $1 \cdot 1 \pm 1 \cdot 0$ & $3 \cdot 1 \pm 3 \cdot 0$ & $14 \cdot 5 \pm 5 \cdot 1 \mathrm{~s}$ \\
\hline$(n=7)$ & $28 \cdot 7,38 \cdot 4$ & b & $30 \cdot 9 \pm 6.8$ & $33 \cdot 3 \pm 11.5 \mathrm{~s}$ & $16 \cdot 7 \pm 8 \cdot 1$ & $3 \cdot 2 \pm 3 \cdot 2$ & $2 \cdot 0 \pm 1 \cdot 2 \mathrm{~s}$ & $86 \cdot 1 \pm 15 \cdot 9$ \\
\hline
\end{tabular}

* Distributed logarithmically.

$+\frac{\overline{\mathbf{x}}}{\overline{\mathbf{x}}-2 \mathrm{~s}, \overline{\mathbf{x}}+2 \mathrm{~s}}$

$\mathrm{a}=$ Sulphated bile acids, $\mathrm{b}=$ non-sulphated bile acids, $\mathrm{s}=$ significant difference compared with children of same age in control group $\mathrm{A}$ or $\mathrm{B}(\mathrm{p}<0.05), \mathrm{C}=$ cholic acids, $\mathrm{CDC}=$ chenodeoxycholic acids, $\mathrm{UD}=$ ursodeoxycholic acids, Mono $=$ monohydroxy bile acids,

Coe = coeliac disease, $\mathrm{CF}=$ cystic fibrosis, $\mathrm{EBA}=$ extrahepatic biliary atresia, $\mathrm{IHC}=$ intrahepatic cholestasis, $\mathrm{SB}=$ short bowel syndrome.

life. The relative quantity of sulphated deoxycholic acids, however, is lower after the first year of life and the total quantity of all deoxycholic acids higher $(\mathrm{p}<0.05)$.

The sulphation rate of the total bile acids was significantly lower in patients with active coeliac disease (Coe) than in gastroenterologically healthy controls of the same age (Table). This decrease was due mainly to the lower values of the monohydroxy bile acid sulphates. Ursodeoxycholic acids were an exception in the group of non-sulphated acids in so far as the portions of these acids in the total bile acid distribution were considerably larger than those of the control group (Table). This increase was due primarily to the shift in the sulphated:non-sulphated ursodeoxycholic acid ratio in favour of nonsulphated ursodeoxycholic acid $(95.3 \%$ vs $85 \%$, see Fig. 1). The shift in the monohydroxy bile acid ratio

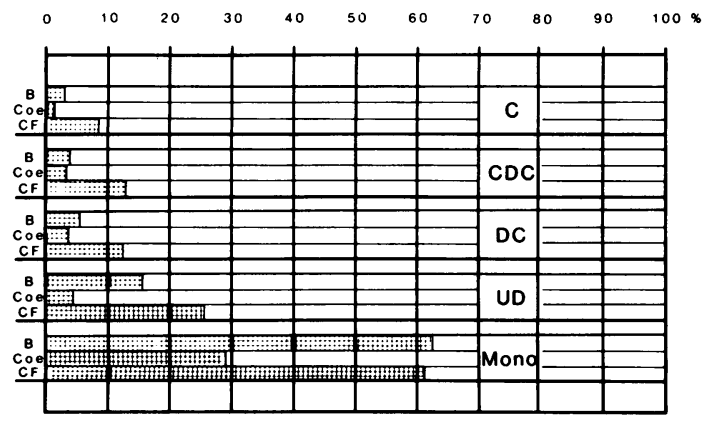

Fig. 1 Percentage of sulphated bile acids in patients with coeliac disease (Coe) and with cystic fibrosis (CF). $B=$ Control group of 24 gastroenterologically healthy children. . sulphated bile acids. For key to abbreviations, see Table.

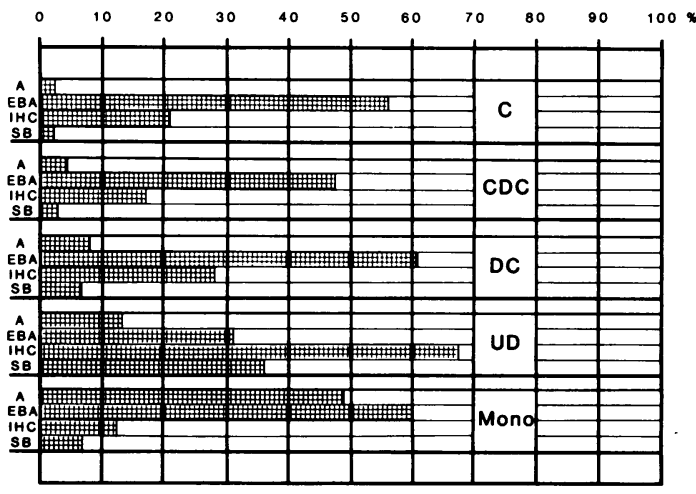

Fig. 2 Ratio of sulphated:non-sulphated bile acids in patients with extrahepatic biliary obstruction (EHO), with intrahepatic cholestasis (IHC), and with short bowel syndrome $(S B)$. $A=$ Control group of eight infants. 
from $61.5 \%: 38.5 \%$ (control group B) to $29 \cdot 1 \%: 70.9 \%$ (Coe), however, was due to a marked decrease of the sulphated portion.

The portion of sulphated bile acids on the whole was higher in our children with cystic fibrosis than in control group B (Table). Statistically significant differences were established only for chenodeoxycholic acids and deoxycholic acids. Compared with the control group, the group of non-sulphated bile acids showed a relative reduction of chenodeoxycholic acids and a significant rise in monohydroxy bile acids. The greatest shift in the sulphated:nonsulphated bile acid ratio therefore occurred with chenodeoxycholic acids, and the least with the monohydroxy bile acids (Fig. 1).

Three patients were included under the rubric EBA,${ }^{32}$ These patients had diminished bile flow into the intestine despite surgery. Even after an intravenous injection of pancreozymin, no more than $0.80 \mu \mathrm{mol} / \mathrm{ml}$ of bile acids were detectable in the bowel lumen. The total bile acid concentrations were somewhat higher in the three infants with intrahepatic cholestasis. In contrast with the infants with extrahepatic biliary atresia, these infants had received phenobarbital $(6 \mathrm{mg} / \mathrm{kg}$ bw/day $)$ for at least three weeks preceding the test. Other drugs known to affect bile acid metabolism had not been administered up to this time.

The sulphation in children with intrahepatic cholestasis was significantly higher than in the control group, a rise which in relation to the distribution of all measured bile acids is primarily attributable to the larger portion of dihydroxy bile acid sulphates (Table). The reduction of cholic acids affected only the non-sulphated acids; the portion of sulphated metabolites remained unaltered. Conversely, the relative increase of the monohydroxy acids was solely because of an increase of the non-sulphated acids. The sulphate portions of the other bile acids, however, were relatively larger than those of the healthy children.

The sulphation for the infants with extrahepatic biliary atresia was twice as high as that of patients with intrahepatic cholestasis (Table). In contrast with the children with intrahepatic cholestasis, the sulphated portions predominated in all children with values a high as $62 \%$ (Fig. 2). The highest sulphation rate, however, was observed in the patients with intrahepatic cholestasis $(68 \%$ of ursodeoxycholic acid was esterified with sulphate).

The relatively high portion of sulphated ursodeoxycholic acid with an otherwise unaltered bile acid distribution pattern in the four children with short bowel syndrome was also impressive (Fig. 2). A comparison with the control group showed that the only further significant change occurred in
Mono. As in the patients with intrahepatic cholestasis, larger portions of monohydroxy bile acids could be detected in the total distribution; at the same time, the non-esterified acids, and not the sulphated metabolites, had risen above the reference values (Table). In accordance with this unilateral increase, the sulphated:non-sulphated Mono ratio was heavily shifted in favour of nonsulphated Mono.

\section{Discussion}

As the method is elaborate and the collection of the intestinal juice specimen involves considerable discomfort for the patient, few standardised studies have been published on bile acid patterns in intestinal juice of children. ${ }^{1633} 34$ In our study as well, the secretin-pancreozymin tests were carried out in the context of a clinically indicated analysis of the functional system of stomach-pancreas-bile and were not performed for the sole purpose of bile acid evaluation. As the analytical method was not changed for several years, a sufficiently large control group was eventually established: eight infants and 24 children who were gastroenterologically healthy on clinical examination. Independent of the age of the child, an average of $3 \%$ to $8 \%$ of all bile acids were sulphated in the first portion of intestinal juice collected after an intravenous injection of pancreozymin $(2 \mathrm{U} / \mathrm{kg})$. The individual acids, however, were variously esterified with sulphate. The lowest sulphation rate was established for trihydroxy bile acids, and the highest for monohydroxy bile acids. Ursodeoxycholic acids (two hydroxyl groups) were remarkable because of their pronounced tendency to esterify with sulphate under both physiological and pathological conditions. The steric structure of the bile acids probably plays an important role in this apparently reciprocal dependency between sulphation rate and number of the hydroxyl groups.

It is conceivable that the activity of the responsible enzyme, a sulphotransferase, is inhibited by the increasing number of space occupying hydroxyl groups. The beta configuration of an $\mathrm{OH}$ ligand apparently facilitates enzyme turnover, as the comparison of the sulphation rate between isomers chenodeoxycholic acids $(3 \alpha, 7 \alpha)$ and ursodeoxycholic acids $(3 \alpha, 7 \beta)$ indicates. In all probability, ursodeoxycholic acids therefore are usually more heavily esterified with sulphate, because the $3 \alpha-\mathrm{OH}$ target group of the enzyme is situated on the other side of the second hydroxyl group and not on the same side of the planar molecule, as is the case with chenodeoxycholic acids.

This rule, however, seems to break down under 
the extreme conditions presented by severe cholestasis. Our studies indicate that, in patients with extrahepatic bile atresia, all bile acids are sulphated to approximately the same degree, thus facilitating and intensifying their excretion in urine and faeces. ${ }^{35-38}$ It is possible that, in these patients, an unknown factor of cholestasis induces maximum sulphotransferase activity which ultimately breaks down the stereometric barriers. While the extent of bile acid sulphation is an indicator of the severity of the bile flow disturbance, our experience indicates that it cannot necessarily be used to differentiate intrahepatic from extrahepatic causes. The new discovery that atypical tetrahydroxy bile acids predominate in intrahepatic cholestasis, but not in extrahepatic bile flow obstruction, ${ }^{1}{ }^{12}$ may prove to be important for the differential diagnosis.

An increase in the monohydroxy bile acid fraction, however, is not necessarily accompanied by intensified sulphation. As children with short bowel syndrome showed no clinical or laboratory signs of cholestasis, cholestasis seems to be the crucial stimulus for the intensification of bile acid sulphation. On the other hand, the potentially toxic monohydroxy and dihydroxy bile acids are not indicators of cholestasis. While their portions were raised in patients with short bowel syndrome, these acids were not proportionally sulphated.

Bile acid sulphates are absorbed from the intestine to a lesser extent than their unesterified parent substances. ${ }^{39}$ This is probably the main reason why they are generally low in patients with active coeliac disease. Reabsorption of these metabolites from the intestine is apparently even further reduced by the mucosal lesions. After renewed passages of the liver, non-sulphated bile acids may predominate in the intestinal juice. Whether, in addition to the established alterations of bile acid metabolism in cystic fibrosis ${ }^{13} 144041$ this slight shift is clinically significant, is a question that requires further investigation.

This paper was presented at the 14th annual meeting of ESPGAN in May 1982, Madrid, Spain.

\section{References}

1 Stiehl A, Becker M, Czygan P et al. Bile acids and their sulphated and glucuronidated derivatives in bile, plasma, and urine of children with intrahepatic cholestasis: effects of phenobarbital treatment. Eur J Clin Invest 1980; 10: 307-16.
2 Back P, Gerok W. Differences in renal excretion between glycotauroconjugates, sulfconjugates and glucuronoconjugates of bile acids in cholestasis. In: Paumgartner G, Stiehl A, eds. Bile acid metabolism in health and disease. Lancaster: MTP Press, 1977: 93-100.

3 Loeoef L, Wengle B. Enzymatic sulphation of bile salts and their derivatives. In: James AT, Morris LJ, New 451-60).

4 Loeoef L, Wengle B. Enzymatic sulphation of bile salts in man. Scand J Gastroenterol 1979; 14: 513-9.

5 Chen LJ, Imperato TJ, Bolt RJ. Enzymatic sulfation of bile salts. II. Studies on bile salt sulfotransferase from rat kidney. Biochim Biophys Acta 1978; 522: 443-51.

6 Bremmelgaard A, Sjövall J. Bile acid profiles in urine of patients with liver diseases. Eur J Clin Invest 1979; 9: 341-8.

7 Loeoef L. Enzymatic sulphation of bile salts in man. Bile salt sulfotransferase activity in human adrenal. Digestion 1981; 21: 297-303.

8 Stiehl A, Thaler MM, Admirand WH. Effects of phenobarbital on bile salt metabolism in cholestasis due to intrahepatic bile duct hypoplasia. Pediatrics 1973; 51: 992-7.

9 Norman A, Strandvik B, Ojamäe Ö. Urinary bile acid conjugates in extrahepatic biliary atresia. Acta Paediatr Scand 1974; 63: 97-102.

10 Strandvik B. Bile acid metabolism in cholestasis of infancy. In: Matern S, Hackenschmidt J, Back $P$, Gerok W, eds. Advances in bile acid research. Stuttgart-New York: Schattauer, 1975: 117-21.

11 Murphy GM, Signer E. Bile acid metabolism in infants and children. Gut 1974; 15: 151-63.

12 Back P. Phenobarbital-induced alterations of bile acid metabolism in cases of intrahepatic cholestasis. Klin Wochenschr 1982; 60: 541-9.

13 Low-Beer TS, Heaton KW, Heaton ST, Read AE. Gallbladder inertia and sluggish entero-hepatic circulation of bile salts in coeliac disease. Lancet 1971; 1: $991-4$.

14 Low-Beer TS, Heaton KW, Pomare EW, Read AE. The effect of coeliac disease upon bile salts. Gut 1973 ; 14: 204-8.

15 Weber AM, Roy CC, Morin CL, Lasalle R. Malabsorption of bile acids in children with cystic fibrosis. N Engl J Med 1973; 289: 1001-5.

16 Roy CC, Weber AM, Morin CL et al. Abnormal biliary lipid composition in cystic fibrosis. N Engl J Med 1977; 297: 1302-5.

17 Burton P. Harper AA, Howat HT, Scott JE, Varley H. The use of cholecystokinin to test gall bladder function in man. Gut 1960; 1: 193-204.

18 Schweizer P. Flach A. Lympho-digestive bile drainage at the porta hepatis in extrahepatic biliary atresia. Experimental study. Z Kinderchir 1976; 18: 271-93.

19 Cronholm T, Makino I, Sjövall J. Steroid metabolism in rats given $\left(1-{ }^{2} \mathrm{H}_{2}\right)$ ethanol. Oxidoreduction of isomeric 3-hydroxycholanoic acids and reduction of 3-oxo-4-cholenoic acids. Eur J Biochem 1972; 26: 251-8.

20 Hofmann AF. Thin-layer absorption chromatography of free and conjugated bile acids on silicic acid. J Lipid 
Res 1962; 3: 127-8.

21 Hofmann AF. Thin-layer chromatography of bile acids and their derivatives. In: James AT, Morris LJ. New biochemical separations. London: Nostrand, 1965: 259 82.

22 Ervard E. Jansson G. Gas-liquid chromatographic determination of human fecal bile acids. J Lipid Res 1968; 9: 226-35.

23 Fehér T, Papp J, Kazil. MH. Spectrofluorimetric determination of individual bile acids in biological fluids: duodenal content and bile. Z Klin Chem Klin Biochem 1973; 11: 376-80.

24 Roseleur OJ, van Gent CM. Alkaline and enzymatic hydrolysis of conjugated bile acids. Clin Chem Acta 1976; 66: 269-72.

25 Burke V, Anderson CM. Bile acid metabolism. In: Anderson CM, Burke V, eds. Paediatric gastroenterology. Oxford-London-Edinburgh-Melbourne: Blackwell Scientific Publications, 1975: 137-42.

26 Niessen $\mathrm{KH}$. Bile acids in duodenal juice of infants and children. Normal values, log-normal distribution, and age-dependence of the total quantity and the distribution of bile acid. Monatschr Kinderheilk 1979; 127: 29-36.

27 Eyssen H, Parmentiere G, Compernolle F, Boon J, Eggermont E. Trihydroxycoprostanic acid in the duodenal fluid of two children with intrahepatic bile duct anomalies. Biochim Biophys Acta 1972; 273: 212-21.

28 Igimi $\mathrm{H}$. Ursodeoxycholate - a common bile acid in gallbladder bile of Japanese subjects. Life Sci 1976; 18: 993-9.

29 Sachs L. Angewandte Statistik. Berlin-Heidelberg-New York: Springer, 1974.

30 Games PA. An improved t-table for simultaneous control on g contrasts. J Am Stat Ass 1977; 72: 531-4.

31 Sidák Z. Rectangular confidence regions for the means of multivariate normal distributions. J Am Stat Ass 1967; 62: 626-33.

32 Altmann RP. Biliary atresia. Pediatrics 1981; 68: 896-8.

33 Challacombe DN, Edkins S, Brown GA. Duodenal bile acids in infancy. Arch Dis Child 1975; 50: 837-43.

34 Goodchild MC, Murplıy GM, Howell AM, Nutter SA, Anderson CM. Aspects of bile acid metabolism in cystic fibrosis. Arch Dis Child 1975; 50: 769-78.

35 Cowen AE, Korman MG, Hofmann AF, Cass OW. Metabolism of lithocholate in healthy man. I. Biotransformation and biliary excretion of intravenously administered lithocholate, lithocholyglycine, and their sulfates. Gastroenterology 1975; 69: 59-66.

36 Cowen AE, Korman MG, Hofmann AF, Cass OW, Coffin SB. Metabolism of lithocholate in healthy man. II. Enterohepatic circulation. Gastroenterology 1975; 69: $67-76$.

37 Cowen AE, Korman MG, Hofmann AF, Thomas PJ. Metabolism of lithocholate in healthy man. III. Plasma disappearance of radioactivity after intravenous injection of labeled lithocholate and its derivatives. Gastroenterology 1975; 69: 77-82.

38 Low-Beer TS, Tyor MP, Lack L. Effect of sulphation of taurolithocholic acid and glycolithocholic acid on their intestinal transport. Gastroenterology 1969; 56: 721-6.

39 Lack L, Weiner IM. Intestinal bile salt transport: structure-activity relationships and other properties. Am J Physiol 1966; 210: 1142-52.

40 Bevan G, Engert R, Klipstein FA, Maldonado N, Rubulis A, Turner MD. Bile salt metabolism in tropical sprue. Gut 1974; 15: 224-59.

41 DiMagno EP, Go VLW, Summerskill WHJ. Impaired cholecystokinin-pancreozymin secretion, intraluminal dilution, and maldigestion of fat in sprue. Gastroenterology 1972; 63: 25-32. 